\title{
(De)Construcción del arte a partir de Ronald Kay
}

\section{(De)Construction of Art through Ronald Kay}

\author{
Elixabete Ansa Goicoechea \\ Instituto de Estética, Pontificia Universidad Católica de Chile. \\ elansa@uc.cl
}

\section{Resumen}

Este artículo analiza la importancia que tiene en la actualidad Ronald Kay para la crítica de arte en Chile y, más concretamente, la relevancia de su texto Del espacio de acá, señales para una mirada americana (1980). Esto se debe a dos propuestas simultáneas que encontramos en sus textos: 1) la posibilidad de realizar una crítica deconstructiva de los imaginarios americanos en Chile, y 2) la continuidad que ofrece a los proyectos constructivos antes del Golpe de Estado en Chile (-1973). El principal objetivo de este artículo es dejar en evidencia la necesidad de volver a una crítica de arte que actualice el legado constructivista en la Historia del Arte; es decir, que visibilice el legado artístico que tuvo y tiene la ambición de transformar el mundo. Kay es un referente importante para dicha labor.

Palabras clave: Ronald Kay, deconstrucción, constructivismo, crítica de arte.

\section{Abstract}

This article analyzes the importance of Ronald Kay in Chilean contemporary art criticism, and more particularly, the importance of his major critical work: Del espacio de acá, señales para una mirada americana [About This Space, Signs for an American Gaze] (1980). Such relevance emanates from two simultaneous proposals in his critical work: 1) the possibility of doing deconstructive criticism of American Imaginaries in Chile, and 2) the continuity his critical work offers to constructivist projects before the Chilean Coup D'état (1973). The main goal of this article is to unveil the need to return to an art criticism that gives continuity to the constructivist legacy in Art History; that is, an art criticism that identifies art works with the ambition to transform reality. Ronald Kay is a major reference for such endeavor.

Keywords: Ronald Kay, deconstruction, constructivism, art criticism. 


\section{Introducción}

\section{Estética vs. poética}

Hace 38 años que se publicó Del espacio de acá, señales para una mirada americana (1980) [Del espacio de acá en adelante], la compilación de textos crítico-poéticos con los que Ronald Kay estableció diversas relaciones entre la fotografía y el arte. Sin embargo, su vigencia perdura en cuanto acoge textos que tratan el tema de la construcción de imágenes más allá de la coyuntura política del momento, aunque con plena incidencia local e inmediata en el contexto social y político en el que aparecieron. En el presente artículo quisiéramos destacar dos aspectos que releyendo Del espacio de acá identificamos como urgentes para la lectura del arte desde el presente: el valor de la "deconstrucción" como aproximación epistemológica para la crítica de la producción artística contemporánea en Chile y el valor de la herencia del "constructivismo" en dicha producción.

Los textos que componen Del espacio de acá tensionan ambas cualidades -la deconstrucción y el constructivismo-, pero de las dos vetas críticas, nos gustaría contextualizar la importancia de la segunda dado que desde la década de 1970 y más prominentemente desde la década de 1980, la deconstrucción como ejercicio epistemológico ha sido ampliamente valorizada. El legado constructivista en la crítica de arte supone, al contrario, un lugar poco visibilizado desde la mitad del siglo pasado. Michel Gauthier evidencia este silencio en su colaboración a la exposición Modernités plurielles 1905-1970 del Centro Pompidou (23 de octubre 2013 - 26 de enero 2015). Esta "Exposición-Manifiesto", como la califica el Director del Centro Pompidou, Alain Sebain, pretende resignificar el canon del arte modernista a nivel a global. Como suplemento a dicho posicionamiento, el catálogo de la exposición incorpora textos de numerosos críticos de arte, cada uno apuntando a diferentes zonas que requerirían ser resignificadas para la crítica del arte ${ }^{1}$. Gauthier explica que desde el aparato crítico de Clement Greenberg (Art and Culture, 1958-1989) el constructivismo (soviético) o/y la herencia del mismo, en tanto expresión artística que plantea acercarse al arte como modo de producción, han sido anulados por lecturas que remiten al arte como aparatos representativos de la realidad, es decir expresiones que no se alejan de proponer una respuesta estética a realidades ya dadas. Gauthier evidencia que para Greenberg los modernismos no conllevan ninguna dualidad que tensione

1 El carácter de "Exposición-Manifiesto" de Modernités plurielles 1905-1970 radica en que, en palabras de Sebain, el Centro Pompidou se "hace global", es decir, "toma la globalización de la escena artística como un tema de reflexión central". A falta de espacio para matizar este tema, que excede el propósito de este artículo, nos gustaría postular que en esta perspectiva global prima principalmente una apertura multicultural cuantitativa. En lugar de plantear un cuestionamiento al espacio museal moderno o a la mediación en el despliegue de obras, prima enfatizar una práctica que podríamos calificar como neo-colonial al centrarse sobre todo en añadir "diversidad" al canon artístico del modernismo a través de incluir en ella obras que en el canon occidental pertenecían a una periferia; es decir, prima la razón imperial de expandir el canon de obras modernistas. 
los lugares estancos de la alta cultura y la cultura popular, el centro y la periferia o la autonomía y la funcionalidad, sino que se asientan principalmente en el interés por la "auto-purificación del arte".

Gauthier estaría planteando un gesto similar al de otro crítico de arte: Boris Groys. En su texto Volverse público: Las transformaciones del arte en el ágora contemporánea (2014) parte por posicionarse en el lado opuesto a la estética, centrada desde La crítica del juicio de Kant (1790), en la percepción del arte. Como consecuencia, Groys inscribe su labor crítica en la poética y en el análisis del legado constructivista en la Historia del Arte; es decir, su interés radica en analizar la tradición que interpreta el arte desde la figura del productor, en la concepción del arte como poiesis o techné. Con ello impulsa una producción artística que no se piense a sí misma únicamente como procuradora de placer o displacer frente a un estado de cosas ya dado, sino constructora y transformadora de dicha realidad. En Del espacio de acá nos gustaría matizar este lugar, no sin antes recoger el valor que también encierra con respecto al trabajo de deconstrucción que alberga de manera simultánea.

\section{Deconstrucción en el arte contemporáneo}

Con Bernardo Oyarzún representando el arte contemporáneo chileno en la Bienal de Venecia del 2017 y presidiendo la colección permanente del Museo Nacional de Bellas Artes en Chile (MNBA) con su obra "Bajo sospecha" (1998), frente al cuadro de la "Fundación de Santiago" (1888) de Pedro Lira, es inevitable mencionar la vigencia que la deconstrucción tiene en la actualidad como ejercicio de visibilización de los discursos e imaginarios de poder, tanto a nivel local como global (Figura 1).

Uno podría decir que fue Ronald Kay con su texto "La reproducción del Nuevo Mundo" de 1978 quien inaugura esta posibilidad en Chile. Allí se planteaba de manera concisa el lugar que la pintura ocupaba frente a la fotografía, similar al que ocupa el lenguaje oral frente a la escritura en la tradición logocéntrica y fonocéntrica occidental. Jacques Derrida en De la gramatología (1967) llamaba archiescritura a la posibilidad de devolverle a la escritura su materialidad; de distanciar a la escritura fonética de sus pretensiones de universalidad que desde Jean-Jacques Rousseau hasta Claude Lévi-Strauss, pasando por Ferdinand de Saussure, se había establecido como hoja de ruta en las relaciones (neo)coloniales que establecía Europa con los países invadidos. La fotografía cumplió, según Kay, esta relación colonial con el paisaje y las comunidades que habitaban el territorio chileno frente al ojo alemán a través de la óptica fotográfica:

Las vistas fotográficas del interior del desierto, las instantáneas panorámicas de la selva o de los extremos de la Antártida, no son reflejo de su consuetudinaria tendencia, sino que implican abruptas irrupciones en el continente desconocido, allanamientos y violaciones visuales de un espacio tramado por mentes otras, 


\section{FIGURA 1}

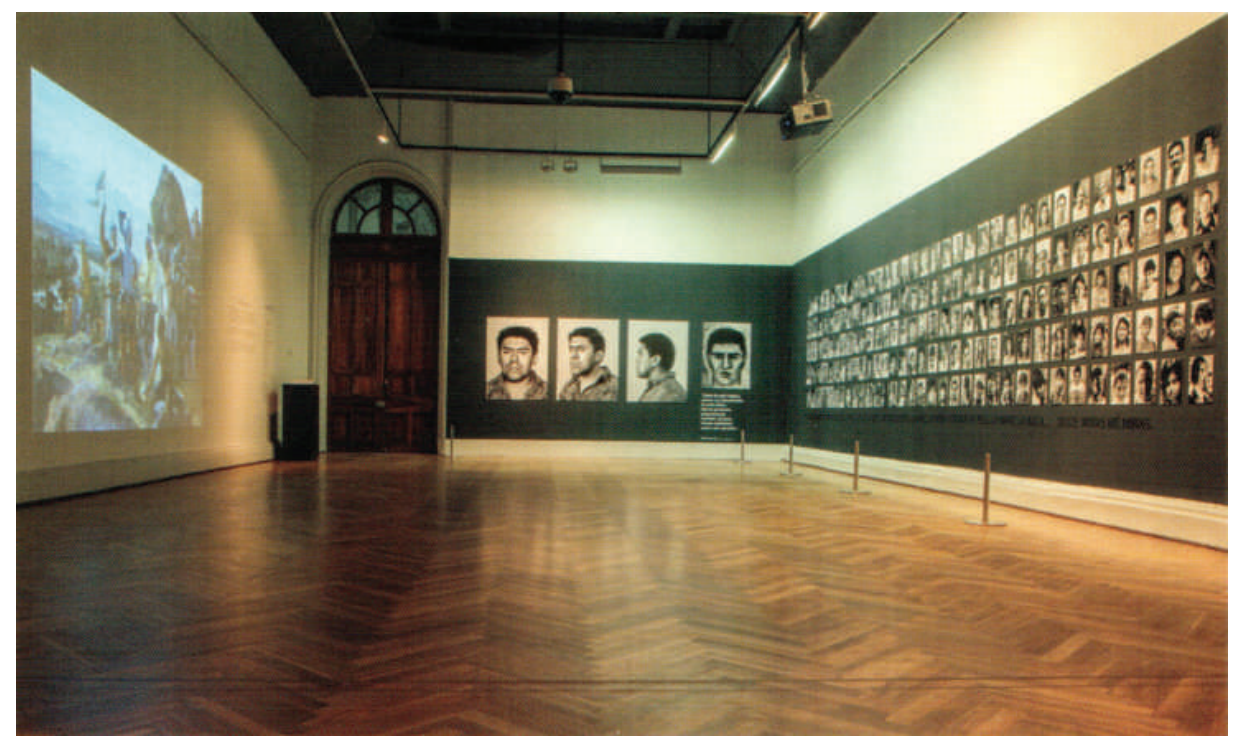

Vista sala "Introducción”, Museo Nacional de Bellas Artes. El Bien Común. Colección MNBA 2017-2018. Santiago de Chile: Museo Nacional de Bellas Artes, 2017. 19.

aborígenes. Estas tomas son señales ópticas de puntos geográficos descubiertos; constituyen piezas de prueba de su real (y no fantástica) existencia; son la noticia documentada de su conquista. A la vez connotan el inventario de lo por dominar, por ocupar, por explotar. Son en cierto modo blancos. Gráficamente, la toma fotográfica en el Nuevo Mundo efectúa una toma de posesión. (29)

La pintura, o el grabado como nos recordará Justo Pastor Mellado en La novela chilena del grabado (1995), parecerían ejercer la labor archiescritural frente al ojo mecánico de la fotografía, que todo invade y reproduce regurgitado como ya Otro. Sin embargo, como muestra Paula Honorato con su curaduría en la revisión de la colección permanente del MNBA, también la pintura se propuso en el siglo xix como óleo escritural, en cuanto alimentaba una estética criolla, muy afín a los gustos burgueses europeos, en la construcción de imaginarios que alimentaran el esparcimiento burgués o legitimaran los lugares de poder y jerarquía impuestos en la colonia, y actualizados en la República. El óleo en sí no siempre es una mancha disidente, como matiza Kay a propósito de la obra de Eugenio Dittborn en el texto "El cuerpo que mancha" (1979). El óleo puede ser también afirmación de un imaginario que desde Europa (o Estados Unidos, a partir de los sesenta) se impone como universal, sea a través de una tradición estética kantiana o de un supuesto gesto vanguardista.

Califico aquí a la vanguardia como "supuesta" ya que, tras la crítica que establece Willy Thayer a los insumos de vanguardia de la Escena de Avanzada en el discurso de 
FIGURA 2

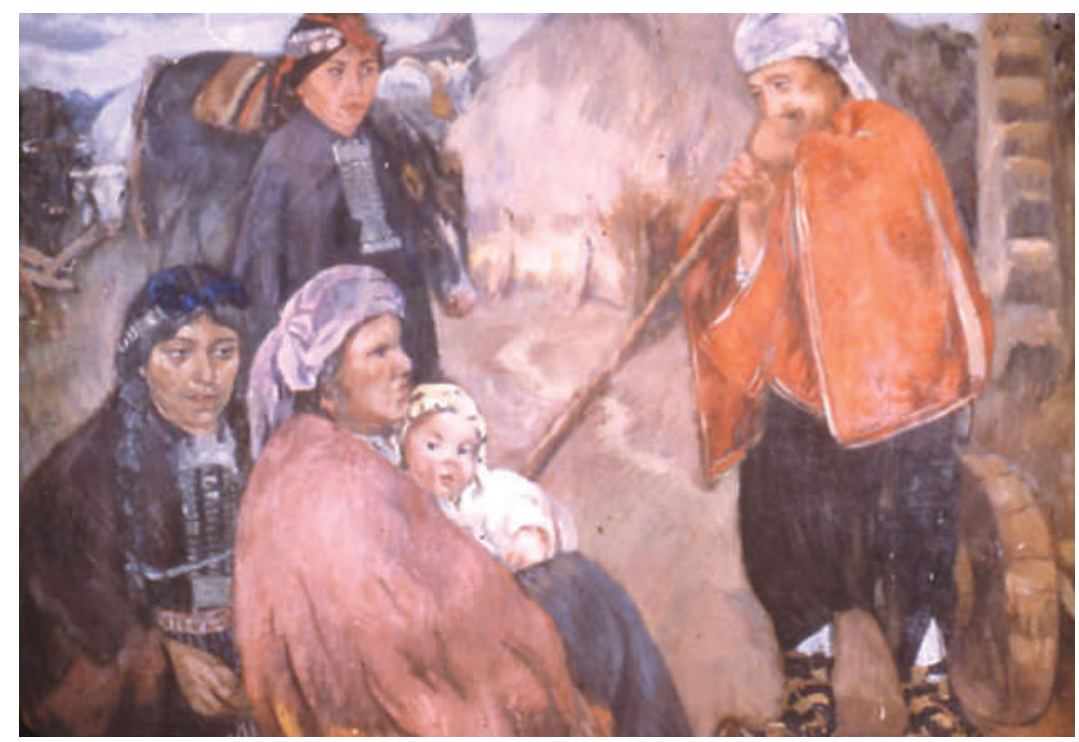

"Familia mapuche" de Carlos Isamitt, óleo sobre tela, año y tamaño desconocido, colección particular. Portal de Artistas Visuales Chilenos: http://www.artistasvisualeschilenos.cl/658/w3-article-40466.html

Nelly Richard recordamos que tanto en los primeros gestos modernistas de comienzos del siglo xx como en los sucesivos gestos abstractos del arte chileno, no hay una ruptura fehaciente con la estética lirista, sino, como explica Thayer, una neofiguración; es decir, una renovación de los procedimientos de producción inherentes al campo artístico, o como ya mencionaba Pablo Oyarzún en una tesis más citada, un simple suceder de modernizaciones.

Esta afirmación se evidencia en la interpretación estética de dos autores con una connotada trayectoria artística en la primera década del siglo xx: Carlos Isamitt (1885-1974) y Ramón Vergara Grez (1923-2012). Son dos ejemplos que, desde un activismo y unas preocupaciones muy dispares a la hora de encarar el paisaje chileno o las comunidades originarias, afirmarían la relación de la pintura con lo que podríamos denominar el óleo escritural. Sus propuestas actualizan el gesto lirista de la fundación de Santiago, aunque como veremos en la siguiente sección, no se limitarían únicamente a eso, especialmente en el caso de Carlos Isamitt (Figuras 2 y 3 ).

Esta propuesta de lectura se basa por un lado en evidenciar el interés "primitivista" de Isamitt a la hora de rescatar la figuración de las culturas materiales de los pueblos originarios con los que convivió. En una entrevista que Juan Emar le realiza el 20 de agosto de 1924, un poco antes de sus residencias en terreno, Emar hace evidente la relación fetichizada que escondería el interés de Isamitt en las formas geométricas originarias, similar a la admiración que vanguardistas europeos, como Pablo Picasso por poner uno de los casos más evidentes, expresaban hacia las formas geométricas 


\section{FIGURA 3}

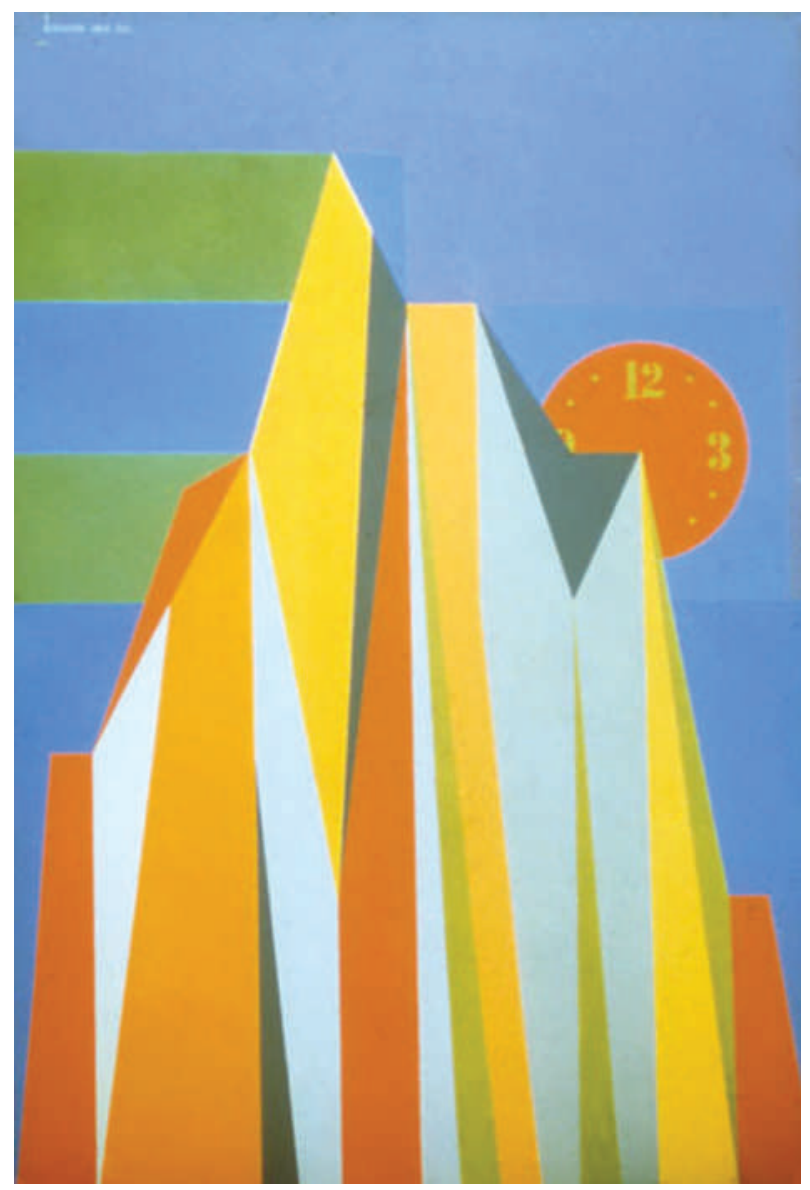

"América despierta a su obra en la luna" de Ramón Vergara Grez, óleo sobre tela, $160 \times 110 \mathrm{~cm}$, año desconocido, colección particular. Portal de Artistas Visuales Chilenos: http://www.artistasvisualeschilenos.cl/658/w3-article-39994.html

del continente africano. Quizás su óleo "Familia mapuche", paradójicamente lejano a la geometría que pretendía buscar, sea la mejor prueba de dicho interés romántico².

En el caso de Ramón Vergara Grez, no estamos frente a un pintor con intereses que excedan la plástica. Por lo tanto, los pueblos originarios simplemente no aparecen en sus cuadros. Lo "andino", por usar el principal apelativo de su obra, proviene de un interés en el paisaje lejano de Mejillones, tierra natal del pintor, que le sirve de inspiración y hoja de ruta estética en su obra. Así se constata, por ejemplo, en el texto que hace las veces de posicionamiento estético-autobiográfico de una de las principales retrospectivas de su obra, "En tránsito a lo autobiográfico" (1997). Con la propuesta

2 Recojo el final de la conversación que mantienen Isamitt y Emar: “[Isamitt]: ‘... Quiero ahora que los verdaderos personajes en mis obras, sean los planos. Y quiero, además, que al solucionar este problema, la obra tenga un carácter local indio, de esos indios que guardan las raíces de nuestro pueblo. Hacia ello se encaminará mi tendencia futura: los planos, las formas sintéticas...' [Emar]: ‘ ¿Usted va hacia el cubismo, Isamitt!' Isamitt ríe” (Emar 105). 
constructivo-geométrica que propone en sus obras, parecería alejarse totalmente de la estética romántica a la hora de representar el paisaje originario. Dentro de la producción constructiva latinoamericana establece relaciones directas con Joaquín TorresGarcía. Hay menciones constantes al valor primordial de la "estructura" geométrica como lugar de experimentación formal: "El paisaje invariable, inmutable y eterno, sólo sometido a los cambios de luz del día y de la noche. La persistencia de los cerros, las quebradas y el acoplamiento de las montañas en la cordillera, contribuían a hacer todavía más riguroso el orden arquitectónico y estructural de este paisaje" (43, énfasis añadido). Frente a la sublimación realista o costumbrista de lo originario, tal y como veíamos con Isamitt, Vergara Grez impone la presencia de lo geométrico-puro como gesto que deshace el ilusionismo anterior.

Sin embargo, en su distanciamiento del neoplasticismo europeo, Grez hace aparecer el mito que difícilmente se despega de una marca romántica:

Nosotros en cambio, [a diferencia de Piet Mondrian o Barnett Newman] vivimos una economía pre-industrial y producimos una cultura mítico-artesanal. Estamos más cerca del hombre y la naturaleza objetiva. A pesar de que sentimos la necesidad de informarnos y realizar experiencias tecnológicas, es mayor nuestro imperativo de vivir experiencias humanas y gozar la poesía. (Geometría andina 24-5)

No hay en Vergara Grez una adhesión a un proyecto chileno o latinoamericanista que responda integralmente a la apertura del arte a la sociedad dentro de los procesos de modernización social de fines del siglo xIx y comienzos del xx. Como se expresa aquí, su preocupación estética se centra en un discurso binario reaccionario entre el centro y la periferia, con una defensa de lo periférico escudada en un imaginario romántico pre-moderno ${ }^{3}$.

Frente a estos óleos escriturales, y evidenciando el ejercicio de deconstrucción que propone Kay, Eugenio Dittborn (1943 - ) parecería deshacerse de todo aquello, o más que deshacerse, visibilizaría frente al espectador la verdad de la invasión paisajísticocomunitaria en la visión del "Nuevo Mundo". Establece referencias directas al bertilloneo como práctica moderna de disciplinamiento de los cuerpos exponiendo su violencia iconográfica, y en algunos casos, como en su serie sobre "Poesía y Costura" o "Reinas" (1978, 1988), revela lo doblemente invisibilizado en el ejercicio de control de los cuerpos: la mujer como ese agente subversivo por excelencia (Figura 4).

3 Cabe apuntar el desconocimiento o nulo contacto entre Vergara Grez y los ejercicios experimentales que se desarrollan paralelamente en la Escuela de Arquitectura de Valparaíso (EAV) con artistas plásticos que tienen también la geometría y el arte concreto como principal lugar de experimentación. La EAV se inscribe en una tradición artística conosureña con mayor conciencia social y un posicionamiento más claro con las posibilidades que tienen el arte y la arquitectura de transformar la realidad existente. Véase Capítulo IV “Arte concreto en Valparaíso. ¿Qué es una exposición?” de Alejandro Crispiani. 


\section{FIGURA 4}

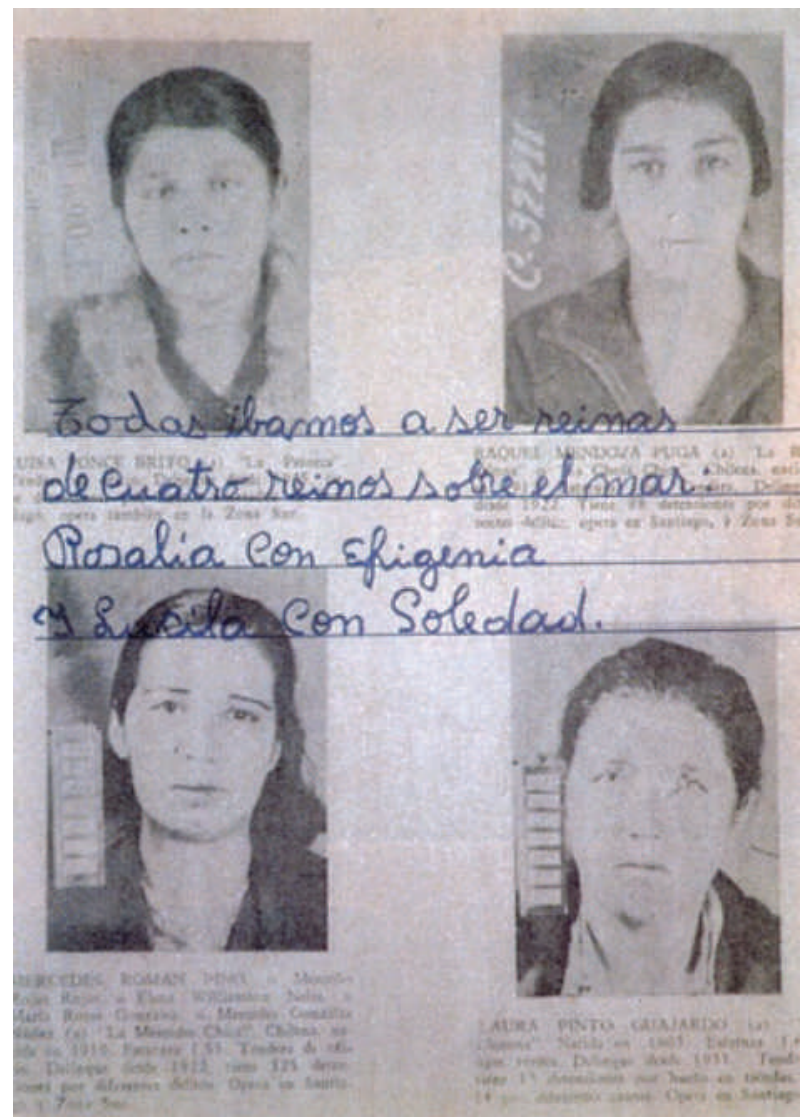

"Reinas" de Eugenio Dittborn, Fotografía, Offset sobre cartón forrado, 60 x $45 \mathrm{~cm}, 1988$, Museo Nacional de Bellas Artes. Portal Memoria Chilena: http://www.memoriachilena.cl/602/ w3-article-80402.html

Para subrayar esta violencia, superpone al bertilloneo expuesto el costoso ejercicio caligráfico de quienes siempre quedan al margen del dictado de la letra. Cito a Kay en su texto "Clases de caligrafía":

La caligrafía torpe, patéticamente escrupulosa de estos anfibios culturales, es de una letra que apenas entiende lo que traza, concentrada obsesivamente durante el acto de escribir en su propia impericia, y, a la vez, poseída por el exhibicionismo en cámara lenta de sí misma, para ostentar un saber casi en vano y a duras penas adquirido, apoyada antes que nada en las líneas de cuaderno de composición, líneas férreas de la institución, más que en la letra del texto, su libertad. (39)

Kay y Dittborn inauguran así a fines de los setenta gestos deconstructivos y marcan un referente importante para otros autores ${ }^{4}$. En el ejercicio de la deconstrucción, la

4 Hemos abierto esta sección refiriéndonos a Bernardo Oyarzún, pero también habría que mencionar obras de autores 
práctica del hacer, el construir, es de alguna manera liberado; no hay deconstrucción que en sí no potencie una poética transformadora de aquellos materiales puestos en suspensión con respecto al uso que la modernidad capitalista les confirió. La cita a Gabriela Mistral en la obra elegida de Dittborn - "Todas íbamos a ser reinas"5 - funciona como el espectro que aparece para recordar otro hacer que difiera del institucionalizado. El gesto adquiere, además, un valor político inmediato en tanto establece, como se ha valorado ya (Mellado), una relación anacrónica que vincula de manera directa la violencia colonial con sus actualizaciones neocoloniales en la República chilena y en el presente de la misma obra, un momento acosado por las desapariciones de la dictadura militar.

Es en vistas a pensar la relación entre el arte y la posibilidad de "transformar" el mundo como nos centramos ahora a pensar el segundo aspecto urgente en el pensamiento de Kay a la hora de debatir su actualidad. Nos remitimos al primer apartado en Del espacio de acá que lleva por título "Materiales de construcción" y se refiere a aquellos materiales propios de las obras de Dittborn, como son las fotografías extraídas de diarios y revistas en desuso, pero también, como aparece bajo el subtítulo "Caja de herramientas" del mismo libro, el offset y la fotoserigrafía, el cartón gris, el óleo (en sus infinitas vertientes líquidas, pintura pero también lubricante industrial), lino crudo, yute, tela de buque, etc. En este segundo momento nos remitiremos entonces al concepto de construcción a partir de materiales industriales desechados.

\section{Construcción poética en el Chile "post-dictatorial"}

Además de inaugurar el ejercicio de la deconstrucción como una manera de visibilizar las jerarquías de poder y la violencia consecuente dentro del logocentrismo europeo, nos interesa plantear que Kay posiciona y se posiciona en su crítica de arte en el ejercicio de la construcción, en la poética en su dimensión transformadora de mundo. Su escritura crítica, junto con la de Nelly Richard como otro referente importante, es ante todo un ejercicio poético, de búsqueda y uso de conceptos, nombres, verbos, adjetivos desbordados y "sucios" en cuanto manchan -tal y como lo hacen, según Kay, los flujos múltiples de Dittborn-, las visiones tradicionales de la crítica de arte, es decir, que "manchan" aquellos relatos puramente académicos o altamente impresionistas, legitimando espacios de poder establecidos. Kay le toma el pulso poético a la crítica de arte y transforma la palabra crítica.

Pero además de transformar la palabra crítica, elige hablar de aquello que precisamente visibiliza una manera del hacer que es imprescindible en el ejercicio artístico

más jóvenes como Felipe Rivas San Martín (su pintura "Patagonia BBC", 2011, por ejemplo) o en general, toda la producción de Sebastián Calfuqueo.

5 La cita completa dice así: “Todas íbamos a ser reinas / de cuatro reinos sobre el mar / Rosalia con Efigenia / y Lucila con Soledad"; véase poema completo en http://www.gabrielamistral.uchile.cl/poesia/tala/saudade/Todas.html 
y que a nuestro parecer cabría volver a pensar en la actualidad. Cuando nos habla del rapto que lleva a cabo la fotografía con respecto a la conciencia de paisaje y agencia subjetiva en la (neo)colonización, Kay enfatiza el potencial constructivo-poético no ya de la pintura, sino también de la propia fotografía:

La historia ha sido expropiada por el dogma de la óptica representativa. La componente ideológica de los medios de información visual tiene aquí su origen. Mientras se mantenga el dogma de la instrumentalidad, o sea, que la relación fotográfica se produce en la evidencia de lo visible como reproducción de suyo comprensible y mientras no se reconozca que ella traza su grafía en el enigma de lo visible, quedamos anquilosados en la repetición de la propia ausencia. Conocerse en la fotografía es, entre otras cosas, reconocerse como efecto de la maquinaria, como fabricación de su construcción. (24)

Kay critica el "dogma de la instrumentalidad" visual y visibiliza el carácter "constructivo" de la fotografía. Es decir, es consciente y plantea abiertamente el debate entre la "estética disciplinaria" y la "poética" para posicionarse claramente en la segunda. Lo hace en un momento arrasado por el Golpe y a través de un artista cuya formación evidencia un "entre" dos mundos: el arte académico con una tendencia a afirmar la estética como principio contemplativo del arte (Escuela de Bellas Artes de la Universidad de Chile) y la producción gráfica que se afirma en la construcción de imágenes con mayor incidencia en lo social (Escuela de Fotomecánica de Madrid). Es este "entre" dos mundos, el del arte y la producción, lo que nos interesa rescatar del interés de Kay en Dittborn y los materiales de construcción citados.

En Chile esta relación data de la segunda década del siglo veinte y está directamente relacionada con un autor ya citado: Carlos Isamitt, quien siendo director de la Escuela de Bellas Artes de la Universidad de Chile en 1928 lleva a cabo una importante reforma a la enseñanza artística originando el reconocimiento de la Escuela de Artes Aplicadas. Esto se lleva a cabo tras sus viajes de investigación abocados al rescate de la cultura local, recorriendo distintas zonas del país (Punta Arenas, Islas de Chiloé,...), pero también tras su paso por Europa en 1925, donde toma cursos en La Sorbona, asiste a una sociedad que se aplica al estudio de la antropología cultural, concurre a las exposiciones de los artistas contemporáneos y como especifica Víctor Carvacho Herrera: "estudia las tendencias artísticas y los fundamentos del purismo holandés manifestado en "De Stijl”, visita Weimar y traba contacto con Gropius que realiza el ensayo de la "Bauhaus" de la que nace la pedagogía moderna en la formación del creador plástico contemporáneo” (ctdo. en Eduardo Castillo Espinoza, 60). Con la visión estético-pedagógica de la Escuela de Artes Aplicadas, que abre sus puertas en 1928, Isamitt es seguramente el primer referente local a la hora de proponer una visión constructivo-productiva del arte en Chile. Es una visión que aúna en un mismo proyecto 1) una reformulación de la pedagogía artística rompiendo con los modelos copistas tradicionales ("Académicos"), 2) una conciencia cultural local y universal en 
la concepción del arte y 3) una conciencia de clase, un deseo de hacer el arte accesible para los sectores populares (Castillo Espinoza, 77).

En estos cruces pedagógico-constructivos la Escuela instruyó sobre las Artes del Fuego, el Metal, la Madera, el Textil y la Gráfica, y también sobre los cursos tradicionales de dibujo, composición, color, historia del arte y estética. Junto con los experimentos de la Escuela de Arquitectura de Valparaíso, constituye la relación más directa en Chile con las posiciones herederas del constructivismo ruso y las escuelas de arte aplicado europeas, como la Bauhaus o la Escuela de Diseño Superior de Ulm (Alemania). Uno de los momentos más importantes en la historia de la Escuela se produce en 1968, bajo la dirección del decano Ventura Galván y con una nueva reforma educativa en ciernes. Los estudiantes exigen una mayor opción educativa en el área de "Arte y Tecnología" en vistas a que el Diseño se constituya en una disciplina reconocida. Esta demanda coincide con la visita de Tomás Maldonado a su país natal, Argentina. Maldonado fue miembro fundador del grupo Arte Concreto-Invención en Argentina en la década de 1940 y dirigió la Escuela Superior de Diseño en Ulm (Alemania) tras la renuncia de Max Bill entre 1964 y 1966. En un encuentro con Ventura Galván, a propósito de su paso por Argentina, Maldonado confirma que Gui Bonsiepe, discípulo de Maldonado y profesor en Ulm, va a incorporar a los planes estatales de la Unidad Popular la práctica del Diseño Industrial en vistas a saciar las necesidades sociales.

Si el acontecimiento de la Unidad Popular supuso un desborde de las instituciones modernas del Estado con respecto al acceso social a ellas, Bonsiepe realiza dicho desborde en las artes a partir de pensar la relación entre arte y producción como una relación disyuntiva; es decir, como una suspensión del concepto de arte burgués y una suspensión también de los objetos y materiales industriales en su deseo productivo mercantil. La idea de Bonsiepe, en este momento inmediatamente anterior al Golpe, no realiza la utopía comunista de Nicolai Tarabukin en los años inmediatamente posteriores a la Revolución Rusa - la transición de la figura del artista burgués a "maestro productivista”, indiferente al obrero de la fábrica (Tarabukin 57)- pero sí supone un acercamiento singular a dicho acontecimiento, actualizando la visión de Isamitt ${ }^{6}$.

Tanto Kay en su pulso constructivo-poético y su interés por el concepto constructivo en el arte, como la obra de Dittborn, en ese lugar disyecto entre el arte y la producción, bien podrían interpretarse como un intento de retomar una tierra baldía tras el Golpe. Los intereses populares y locales suscitaron desde el comienzo de la Escuela de Artes Aplicadas críticas sesgadas por la "instalación de 'doctrinas

6 Sin salir de la propia crítica de arte, recordemos la tesis de Willy Thayer: "36. Entre 1970 y 1973, fue el gobierno popular de Salvador Allende el que se constituyó en sujeto transgenérico de la vanguardia. El gobierno popular operó, desde la representación, el descontrol programático de la representación en la teleología de la revolución. El descontrol programático de la representación puesto en el telos de la revolución, tuvo su hipérbole y cifra siniestra en La Moneda en llamas que recorrió el planeta videada y fotografiada en colores y en blanco y negro. La Moneda, La República, el Estado en llamas es, a la vez, la representación más justa de la voluntad de acontecimiento de la vanguardia, voluntad cumplida siniestramente por el golpe de Estado como punto sin retorno de la vanguardia, y big-bang de la globalización" (48, énfasis añadido). La labor de Bonsiepe la situamos en el momento de "descontrol programático de la representación" durante la Unidad Popular. 
bolcheviques"' como denomina Eduardo Castillo Espinoza en su recuento de la historia de la Escuela de Artes Aplicadas (82). De hecho el cierre de la Escuela tiene que ver con el rechazo de parte del régimen de prolongar cualquier espacio que se acercara a discursos ideológicos "populares", especialmente aquellos que supusieran un desborde de lo instituido. Dittborn y Kay en el momento que se publica Del espacio de acá podrían pensarse entonces como lugares desde donde pensar no tanto el quiebre con las propuestas constructivo-poéticas del arte chileno, sino un continuum complejo dentro de las circunstancias en las que se arrasa con los horizontes utópicos de transformación social. Las fotografías extraídas de diarios y revistas en desuso, el offset y la fotoserigrafía, el cartón gris, el lubricante industrial, el lino crudo, el yute, las telas de buque, construyen a partir de deshacer y deconstruir el impulso productivomercantil de los mismos, más si en ellas vemos plasmados los rostros violentados de un cuerpo siempre invisible, el mismo que en las propuestas de Isamitt o Bonsiepe configuran como principal agente desbordador del desarrollo capitalista moderno.

El único ensayo crítico que en los últimos años se ha propuesto abordar la relación entre arte y producción a propósito de los discursos de vanguardia en el arte contemporáneo chileno es Modos de producción. Notas sobre arte y trabajo (2011) de Federico Galende. Su posición parte por desacreditar en los esfuerzos constructivistas rusos ningún efecto desbordante y superador del desarrollo capitalista moderno que deshiciera las diferencias entre artista y proletariado. Traduce dichos esfuerzos como siempre parte de cierto "izquierdismo realista de partido", el "arte realista del mensaje" (30-31). Una lectura similar ofrece con respecto a la panorámica que dibuja sobre los discursos de la (neo)vanguardia en la crítica de arte chilena.

Galende cita a Ronald Kay, Enrique Lihn y Nelly Richard como los principales referentes críticos que se hacen cargo de los esfuerzos que desde los sesenta se venían gestando en la producción artística chilena en sus intentos por llegar al "grado cero de la intención artística” (33), cuando Francisco Brugnoli, José Balmes y el grupo Signo cuestionan con sus obras los modos de producción artísticos. Galende se detiene a afirmar la importancia de Nelly Richard entre los críticos citados para afirmar que su posición además de evidenciar los modos de producción e intencionalidad propios del concepto de autor burgués, produce un quiebre con lo que en referencia a la vanguardia soviética entendía como arte realista: "Márgenes e instituciones es un libro que puede leerse perfectamente como un pequeño manifiesto contra las ofensivas esteticistas del poder totalitario de la época, pero también contra las estéticas regresivas del viejo izquierdismo dogmático vinculado al 'arte comprometido"' (34-5, énfasis añadido). Efectivamente en Márgenes e instituciones y más concretamente en el capítulo "La exterioridad social como soporte de producción de arte", se plantea la tesis de que tanto Francisco Brugnoli como lo que Richard denomina "Brigadas Muralistas integradas por J. Balmes, G. Barrios, A. Pérez, G. Núñez, R. Matta, etc.” (63) hacen persistir una "tradición de realismos que subordina ilustrativamente la imagen a los contenidos del mensaje ideológico" (64). Richard erige la "Escena de Avanzada", refiriéndose al 
grupo CADA, Carlos Leppe, Diamela Eltit, Raúl Zurita, Eugenio Dittborn, Juan Dávila y Gonzalo Díaz, entre otros, como contraposición a lo que, haciendo tabula rasa de la producción artística heterogénea que existía antes del golpe, se produciría como expresión demasiado apegada al programa político de la Unidad Popular. Entre aquella heterogeneidad aquí hemos querido referirnos a los lugares nacionales y regionales que desestabilizaron el concepto de arte en un gesto heredero del constructivismo ruso, localizable en la visión de Isamitt con el proyecto de la Escuela de Artes Aplicadas de la Universidad de Chile, en el grupo Arte Concreto-Invención argentino con Tomás Maldonado a la cabeza, en Gui Bonsiepe, y también, en el carácter (de)constructivo de las obras de Eugenio Dittborn y Ronald Kay. Del espacio de acá nos recuerda que hay una labor importante del constructivismo local antes y después del Golpe, y que el lugar del arte como constructor de realidad ha de ser retomado en la actualidad.

\section{Referencias}

Castillo Espinoza, Eduardo, ed. Artesanos, artistas, artífices. La Escuela de Artes Aplicadas de la Universidad de Chile, 1928-1968. Santiago de Chile, Ocho Libros y Pie de Texto, 2010.

Crispiani, Alejandro. Objetos para transformar el mundo: Trayectorias del arte concretoinvención, Argentina y Chile, 1940-1970. Santiago de Chile y Buenos Aires, Ediciones ARQ y Prometeo, 2011.

Derrida, Jacques. De la gramatología. México, Siglo XXI, 1986.

Emar, Juan. Jean Emar. Escritos de arte (1922-1925). Recopilación, selección e introducción, Patricio Lizama. Santiago de Chile, Dirección de Bibliotecas, Archivos y Museos, 1992.

Galende, Federico. Modos de producción. Notas sobre arte y trabajo. Santiago de Chile, Palinodia, 2011.

Gauthier, Michel. “A Brief History of Modernism.” Multiple Modernities 1905-1970. Ed. Catherine Grenier. Paris, Éditions du Centre Pompidou, pp. 32-34.

Groys, Boris. Volverse público: Las transformaciones del arte en el ágora contemporánea. Buenos Aires, Caja Negra, 2016.

Honorato Crespo, Paula. "El Bien Común. Colección Museo Nacional de Bellas Artes”. El Bien Común: Colección MNBA 2017-2018. Santiago de Chile, Museo Nacional de Bellas Artes, 2017, pp.16-35.

Kay, Ronald (1980). Del espacio de acá. Señales para una mirada americana. Segunda Edición. Santiago de Chile, Metales Pesados, 2005.

Mellado, Justo Pastor. La novela chilena del grabado. Santiago de Chile, Editorial Economías de Guerra, 1995.

Oyarzún, Pablo. Arte, visualidad e historia. Santiago de Chile, La Blanca Montaña, 2000. Richard, Nelly (1986). Márgenes e instituciones. Santiago de Chile, Metales Pesados, 2007. 
Seban, Alain. "Plural Modernities From 1905 to 1970. 23 October 2013 - 26 January 2015. Interview with Alain Seban, President of the Centre Pompidou By Stéphanie Hussonnois". Artmap Foundation. Recuperado de https://artmap. com/pompidou/exhibition/plural-modernities-from-1905-to-1970-2013 (09 de agosto, 2018).

Tarabukin, Nikolai. El último cuadro. Del caballete a la máquina / Por una teoría de la pintura. Trad. Rosa Feliu y Patricio Vélez. Barcelona.

Thayer, Willy. "Del aceite al collage". Cambio de aceite: pintura chilena contemporánea. Ed. Francisco Brugnoli. Santiago de Chile, Ocho Libros, 2003, pp. 42-59.

Vergara Grez, Ramón. Geometría Andina. Santiago de Chile, Museo Nacional de Bellas Artes, 1997. 